\title{
Observation: A lean tool for improving the effectiveness of Lean Six Sigma
}

\author{
V.Arumugam and Jiju Antony \\ Department of DMEM \\ University of Strathclyde \\ Glasgow, Scotland \\ Alex Douglas \\ Liverpool Business School \\ Liverpool John Moores University \\ Liverpool, $U K$
}

\begin{abstract}
Purpose-The purpose of this paper is to propose a robust 'observation' procedure drawn from the social science research literature for adoption in a Lean Six Sigma project setting. A case study illustrates the application of the proposed observation procedure in a Lean Six Sigma project undertaken in a European airport to improve process speed and reduce variability.
\end{abstract}

Design/methodology/approach-Literature review and case study process information from a real project.

Findings-The study finds that by utilising 'observation', which is basically a Lean tool, not only is speed increased by eliminating waste, but also it helps to identify the root causes of variations in the output quality characteristics, whose reduction is the main objective of a Lean Six Sigma programme.

Research Limitation and implications-The proposed approach has been applied and tested in a transactional Lean Six Sigma project. Its applicability to a wider context needs to be established through more case studies in both manufacturing and transactional environments. 
Practical implications-Critical observation has a profound impact both on the organization and its people. It improves organizational learning, promotes employee involvement and offers experiential learning to employees. This study may inspire managers to provide motivation for people to engage in observational activities by imparting structured training on observation. The employees may be motivated to become involved in observational activities as selfdirected actions to improve the employees' effectiveness.

Originality/value-This paper is an interdisciplinary study drawing knowledge from other branches of social research and adopting it in Quality Management. By a case study approach, this paper explains how 'critical observation', a tool used both in Lean and Social Research enhances the power of Lean Six Sigma.

Keywords: Observation, Lean, Six Sigma, Tools, Techniques

\section{Introduction}

Lean and Six Sigma are both process improvement methodologies. Although Lean and Six Sigma both have a set of proven tools and techniques, they are not to be viewed as a collection of tools or practices, but rather business improvement strategies (Antony \& Banuelas, 2002; Kumar et al., 2008) which use appropriate tools and techniques. Lean is about speed and efficiency and Six Sigma is about precision and accuracy. Both are complementary in nature and when combined, Lean and Six Sigma tackle process inefficiency (Lean) and process variation (Six Sigma) as a single effort. Lean focuses on eliminating non-value-adding steps and activities in a process, and Six Sigma focuses on reducing variation from the remaining value adding steps. What evolves as a result of this combination is Lean Six Sigma (George, 2002) which provides us with a powerful tool for breakthrough improvement. 
Tools and techniques are important for an effective problem solving process. Some of them are easy to use and some are complex and advanced, which may require the acquisition of special skills and expertise on the part of the people wishing to use them. Tools and techniques are only a means, and not the solutions to the problems, and the appropriate selection of these tools and techniques, based on situations and objectives of the project, will ensure and enhance the project outcome.

A number of Lean tools have been adopted by practitioners of Lean Six Sigma, along with the Six Sigma tool set. These Lean tools coupled with other tools of Six Sigma are used in various phases of the Six Sigma methodology, and these tools often improve the effectiveness of the Six Sigma approach by identifying wastes (or non-value-adding activities), the origin of that waste, and help eliminate that waste by improving the process speed and therefore the efficiency of the process.

Some Lean tools, however, not only help to increase speed by eliminating waste, but also help to identify the root causes of variations in the output quality characteristics, whose reduction is the main objective of a Six Sigma programme. One such tool is 'Observation'. Drawing on the literature of social science research, this study proposes a robust observation procedure for adoption in Lean Six Sigma project settings.

The rest of the paper is organized as follows. Section 2 traces the use of observation in social science research and section 3 briefly discusses the tools and techniques of Six Sigma and Lean. Section 4 examines observation in the context of Lean Six Sigma and section 5 provides some guidelines. Section 6 describes and discusses a Lean Six Sigma case study, which explains how 'observation' helped to improve the process speed and reduce variations in the process. The paper concludes with a note on managerial implications and further research agenda. 


\section{Observation in Social Sciences Research}

Observation remains one of the foremost tools in scientific studies from the early stages of human development. Development of astronomical theories and the theory of the universe have all evolved by continual reasoning, observations and interpretations. The emergence of the 'gravitational theory' from Newton's observation of the 'falling apple' is a fitting example on the role of observation in scientific theorizing. Origins, acceptance, generalizations, falsifications or rejection and modification of various scientific theories are based mainly on observations, followed by scientific reasoning and interpretations (Machamer, 1970).

Observation is more than seeing, as exemplified by the famous quote of Sherlock Holmes to Dr. Watson: 'You see but you do not observe' (Conan Doyle, 1891). Seeing is a necessary condition for observation but not sufficient, and the observed information should be in a communicable form for any decisions (Machamer, 1970). Observation is done through one or more of the observer's senses to collect the relevant data. It also involves the use of careful, methodical plans for the selection, recording and encoding of that set of behaviour, settings or actions, which is consistent with empirical objectives (Weick, 1968). Observation is seeing with a purpose and that purpose dictates the other associated activities of observation. Further, observation is related to some physical activity or phenomenon.

Observation as a data collection methodology has been widely used in almost all social science research, especially in applied psychology fields such as clinical, educational and developmental studies, marketing research and, to a limited extent, in organizational studies (McCall, 1984). Empiricist tradition or empiricism suggests that only knowledge gathered through experience and the senses is acceptable, and the idea must be subjected to the rigours of testing before it can be considered as knowledge (Bryman, 2001). The premise in a social research setting is that almost all social phenomena can be observed by humankind. The main 
purposes of observation are to: (1) anchor the development of theories; (2) test a specific hypothesis; and (3) evaluate and revise existing theories (Machamer, 1970; McCall, 1984).

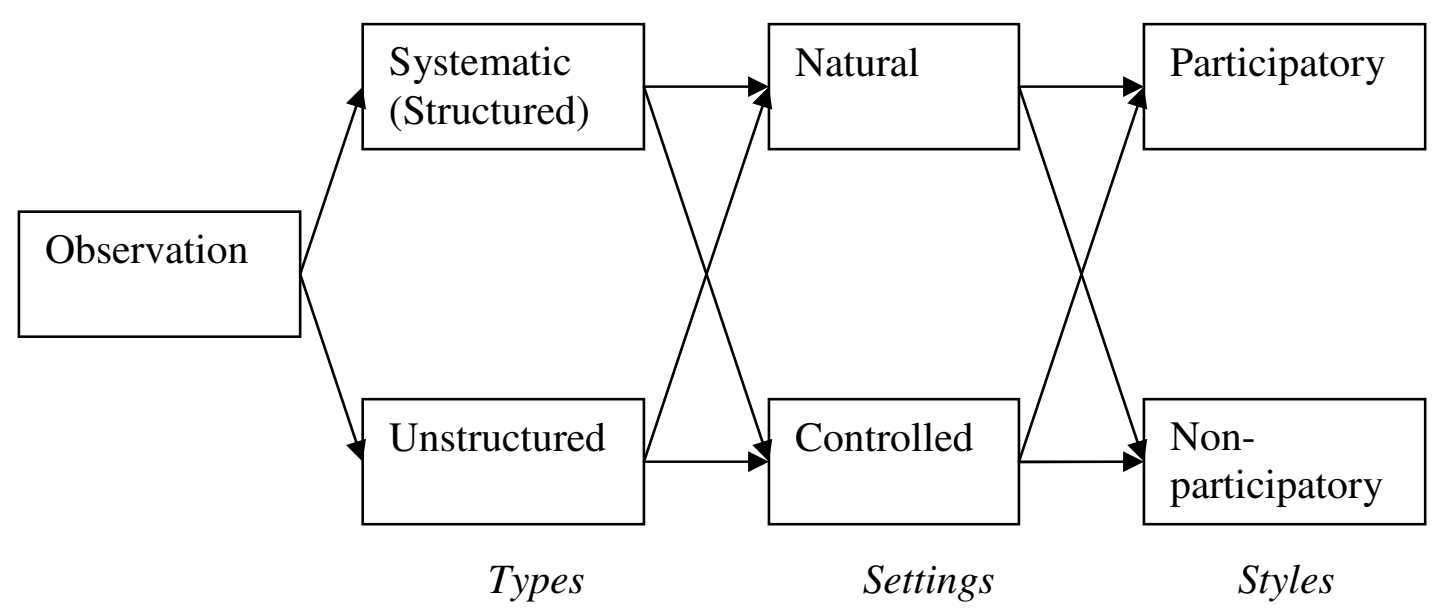

Figure 1 Categories of Observation

Different types of observation are found in social science research which is displayed schematically in Figure 1. (developed from Malhotra, 1999). The origin of using structured observation (Systematic) in social research can be traced back to the 1920s, when researchers showed an interest in studying the social behaviour of children. Systematic field observations found their modern form through sociologist in the early 1930s, and a further push came from clinical psychologists and the methodology developed by biologists (McCall, 1984). The renewed interest in 'direct' observation as a research method in managerial research can be attributed to Mintzberg's work (Mintzberg, 1973; 1979), on five Chief Executive Officers' behaviour (Martinko and Gardner, 1985). Participatory observation has its roots in social anthropology, and finds less usage in management and business research (Saunders et al., 2000).

In structured observation, the observer has a certain framework which is pre-decided, regarding what to observe and what to record, and what type of incidents to observe etc. During or after the observation, things which are observed and important are recorded for analysis and for any subsequent conclusions. 
Since observation is influenced by the observer's prior knowledge and their assumptions and paradigms, researchers in many fields like anthropology, sociology and ethnography, adopt observation along with traditional qualitative research methods, such as interviews and group discussions, to improve the data collection (Saunders et al., 2000; McCall, 1984). In research settings, observations need to be accurate, objective and without any bias, and observers must avoid making any opinions on observed things based on their background knowledge and perceptions. Strengths and limitations of 'observation' are given in Table 1.

Insert Table 1 here

Although the requirements and the purpose of observation in social research are different from those of Lean Six Sigma project settings, the basic approach of observation and the different methods practised in that field can be adopted along with those practiced in the Lean environment to suit the purpose of a Lean Six Sigma project.

\section{Tools and techniques of Six Sigma and Lean}

\section{Six Sigma}

In Six Sigma, process improvement projects are conducted through DMAIC, a structured methodology which stands for Define, Measure, Analyse, Improve and Control. This DMAIC methodology is consistent with Deming's Plan-Do-Check-Act (PDCA) cycle (Pande et al., 2000; Montgomery and Woodall, 2008). In the Define phase, the team defines what is important in terms of Critical to Quality (CTQ) through Voice of the Customer. This helps to identify the specific process to be focused on and the team is directed to understand the process through tools such as process maps and flow charts. The team is able to set the objective, both in terms of performance levels and financial gains, and the team is now ready with a well-documented project charter with clear goals, a definite timeframe and, associated milestones. The Measure 
phase structures and directs the activities of the team through techniques like capability studies, Statistical Process Control, Measurement System Analysis, Cause and Effect diagram, Cause and Effect Analysis, data collection etc., to identify many possible variables affecting the chosen CTQ. In the Analyze phase, tools like hypothesis testing, regression, multivariate methods, Failure Mode Effect Analysis (FMEA), Design of Experiments (DOE) etc. direct the team to analyse data objectively and arrive at a vital few variables causing and affecting the CTQ, as well as guidance on selecting a set of possible solutions. In the Improve phase, techniques like DOE and brainstorming help to select and implement solutions. The Control plan and SPC etc. help the team during the Control phase, to control the process and sustain the gains obtained.

\section{Lean}

The Lean production philosophy seeks to minimize unnecessary time, material and efforts in the production processes and results in improved speed of the process (Liker, 1996; Womack and Jones, 2003; Bicheno, 1999). This philosophy was widely popularised in Japan in the early 1950s by Taiichi Ohno and his team and was called Toyota Production System (TPS) and later became to be called as Lean (Womack et al., 1990). Lean simply means streamlining the flow of production material throughout the value stream by reducing cycle time wherever possible, and the tools and techniques of lean actually are designed to reduce the processing time (Standard and Davis, 1999), by reducing or eliminating all seven waste elements (Transport, Inventory, Motion, Waiting, Overproduction, Over-processing, and Defects). Observation' and '5 Whys' are tools from the Lean toolbox, which help to attack both process waste and process variability. They help to identify not only the waste and its origins but also help to identify one or more possible causes of variations of product characteristics.

\section{Observation and Lean}

Observation is the most basic tool which, when practiced and used effectively, can lead to breakthrough improvement being obtained. Shigeo Shingo, one of the architects of the Toyota 
Production System (TPS) once said: "The problem is not elimination of waste, but identification of waste". For identification of waste, Taichi Ohno, another architect of TPS who used to train his people by putting them in the actual workplace to find out what was actually happening, often instructed his people: "Observe the production floor without preconceptions and with a blank mind; repeat 'why' five times to every matter". In fact it is reported that Taichi Ohno had a habit of training his subordinates in observation by asking them to stand together for hours within a circle marked on the factory floor, to watch the process and think for themselves about what they were seeing, to question, analyse, and evaluate. He was teaching the power of 'deep' observation (Liker, 2004).

Toyota people often use the Japanese term Genchi Genbutsu meaning 'go and see for yourself to thoroughly understand the situation'. Genchi means 'actual location', Genbutsu means 'production' or 'material', and the two words jointly mean 'going to the workplace to see for understanding, and grasp the actual situation'. Gemba is another popular term for 'workplace'. In Toyota's approach, people are expected to go and find out the facts for themselves before talking about the issues involved, and each individual is responsible for what he or she is talking about and reporting.

Liker (2004) in his book, Toyota Way, written from his findings from visits to many Japanese Toyota plants, and from interviews he conducted with many people at Toyota, gives details of the Toyota way under 14 management principles. While he is talking about the importance of observation, as seen in Toyota factories, he concludes that observation leads to deep understanding of the process which results in improved knowledge and that helps to make reasoned decisions and ultimately become a true learning organization.

\section{Observation in the context of Lean Six Sigma}

Observation in Lean Six Sigma involves an investigator viewing a process or activities of people and/or equipment and registering, by some means (either noting down or registering in 
mind), for subsequent critical analysis to come to a meaningful and logical conclusion on some clues, which are the potential causes of variation in the process outcome.

The intention is to identify those actions, factors, people and layout, as well as such things as process interfaces, which might contribute to the variance of the outcome, and those which might constitute 'non-value-adding' activities (or waste), as viewed from a customer's perspective. In project settings, in addition to objective observation without any pre-conditions, the aim should be to identify what happens in the overall functioning of the process, compared to what should happen in an ideal situation. In order to achieve these two objectives, observation processes for Lean Six Sigma need to draw on practices from both Lean and Social Science research settings.

If observation is used exclusively to identify waste and the origin of waste in the Lean context, and to identify all possible factors or culprits causing variance in the characteristics of the output, the scope of the observation needs to be extended to cover the following:

1. Identifying the differences in activities caused by various elements, operator or machine or both, of a process over a period of time (Changes with respect to time);

2. Identifying whether the process varies as a result of something else which mediates or moderates the behaviour of the observables (Changes with respect to different environmental and contingency factors).

Accordingly, it is advised that only structured observation should be used to meet these twin objectives so that a proper sampling plan and a detailed procedure for observation and collection of data are available.

Observation, however, is conditioned by the observer's interests, preferences, beliefs and prior knowledge (Toretti, 1986), and so it is logical that the findings can only be taken as a 
possibility, as the same thing will be understood differently by someone else. Furthermore, the Six Sigma philosophy advocates decisions based on data (Pande et al., 2000; Harry and Schroeder, 2000), and so the findings can only be treated as clues, which later need to be ascertained statistically, for their validation, with the relevant data collected during Measure phase of DMAIC.

\section{Guidelines for observation in Lean Six Sigma project}

Observation is generally carried out during the Measure phase of the project, after gaining some basic understanding of the process in the Define phase.

\section{Planning and preparation:}

It is necessary to acquire basic knowledge about the process from a process flow chart and process members, including its various elements, the activities carried out by people, interactions and interfaces, process settings, floor layout, material and information flow.

It is advisable to do a small, unstructured pilot observation before going in for fully fledged observations. This will help to: identify various interactions that are inherent in the process; find out the time during which some disturbance comes into play; and discover various variables or factors which might have been overlooked during the Define phase. Based on the above, prepare a basic framework of observation including: what to observe; when to observe; the frequency to cover all factors which govern the process; The required number of observers is decided based on the complexity of the process, and all of them are required to be well informed of the procedures and framework developed.

\section{Observation process, including recording and documentation of observation:}

Viewing a process can be done by an observer or by some recording equipment like video camera (where senses are extended by various instruments or equipments), when physical observation by people is difficult. This first type is termed 'direct observation' and the second 
'indirect observation'. A combination of both these observation types may be a better option sometimes, as things which have gone unnoticed by the observer may have been captured by the recording equipment. Some process activities can happen simultaneously or may be interrelated, and in such cases the observer could see only what is visible to her/him. Question sessions with the process people after the observation sessions can improve the outcome of the observation in these situations.

It is always found that the trained observer, with some basic knowledge about the process being observed, will observe more things than will of a person with less or no knowledge. Also, some may observe with their own preconceptions, which may influence the observation. Multiple observations, such as one or more observations of similar kind by more than one observer can help overcome this problem and additionally it improves the triangulation of data. Simultaneous observation by more than one observer, followed by question sessions with the process people, will help to improve the understanding of the entire process and make valid judgement on the clues. It is essential to record what is observed, and not what the observer perceives, based on his knowledge or prior information. The exclusive recording of the observation, without any mix up of the observer's view or perceptions, will also be required during the Improve phase of DMAIC.

\section{Exploring the observed information and analysis:}

It is advised that analysis be done soon after the observation, as some of the observed items may not have been noted down, owing to the nature of the observation being too complex to be written down, and may reside only with the observer in their memory. So the analysis needs to be done before the memory fades.

The project team then discusses the project objectively through brainstorming sessions, with all the information gathered through observation, group knowledge, and general theoretical background, to identify clues on possible and potential causes of variations. They then 
document them and prepare plans for quantitative data collections for further explorations. If some more clarification is required, further observation may be conducted to substantiate and validate the earlier findings.

With the collected data and the findings from the observation during the Measure phase, the team explores, generates hypotheses and verifies the critical causes during the Analyse phase (Pande et al., 2000). Using data, experimentation or further process analysis during the Analyse phase, the team establishes and verifies which of the potential causes contribute significantly to the problem.

\section{Case study - Airport Security Check Process}

\subsection{Problem}

Project: Reduction in waiting time in the security check area and reduction in the variation of all activities in the security check process in a major airport.

The project was undertaken in the year 2007, at one of the busiest airports in Europe. For confidentiality we call the airport as Alfa. Its antiquated buildings were not designed to meet the traffic volumes and the customer demands. As such it was not providing a good experience to customers' expectations except the basic need to get them from point A to point B.

This situation was exasperated by the new security alert (during August, 2006) and the subsequent guidelines stipulating additional security check processes such as,

- Removal of liquid/fluid material from hand luggage (measuring beyond100ml in volume)

- Removal of jacket, shoes, belts etc. for scanning through the X-ray machine along with hand luggage.

- If a passenger has more than one hand baggage, one has to be put into the other. 
- Searching of the entire items if required.

Because of the risk, new guidelines were given daily and this dynamic change made guards very cautious, resulting in delay and increased queue time. Increasing the total number of security personnel did not help to improve the situation either.

A Lean Six Sigma Project was initiated to study the security check process and implement suitable changes in order to reduce the queue time and improve the passenger experience. The project was under taken in two phases. The first phase (our case study) was to study and understand the process and suggest improvement for 'quick wins' and to identify all potential causes which would form the basis for phase two. We will not discuss about the phase two of the project which is beyond the scope of our case study here.

Target: Average waiting time of the passenger in the security check process should be less than 6 minutes at least $95 \%$ of the time (measurement frequency: every 5 minutes).

Defect: Queuing time of more than 6 minutes.

Customer processing: Complete security check-up of passengers and their handheld baggage and other personal belongings carried to the cabin.

\section{Process:}

Figure 2 shows a typical layout of a set of security check lanes with an expanded view of the process flow. On completing passport control, the passengers (customers) go through the security check and put their hand baggage and personal belongings, such as phones, purses, belts, shoes, and jackets on the conveyor belt, which then pass through the scanning system. The passengers go through the metal detector, and once the customer processing is complete, they come out of the process boundary. Process members (six people) change positions every 
20 minutes. This is a legal requirement to avoid strain on the people viewing the screening machine.

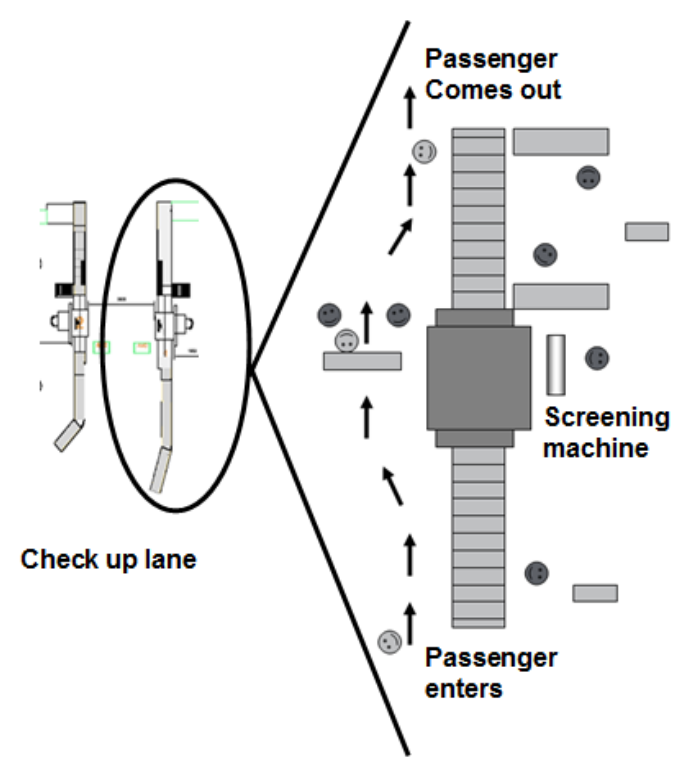

Figure 2. Typical security check process

\subsection{Observation carried out by the project team:}

1. Understanding the process

- Study of the process flow chart;

- Discussion with process owners and team leaders about people in the process, their activities and various interfaces related to the process, and the number of workstations and their interrelationship.

2. Pilot unstructured observation at two terminals of the airport:

(Findings added in the final structured observation framework)

- Rotation of process members' positions and how they affect the process behaviour;

- Reaction time for delayed/unplanned arrival;

- How serviced customers affect the process flow and performance.

3. Final structured observation conducted of three lanes, for two hours each, in two shifts:

- Observation on process people's mobility and their activities; 
- Activities of customers;

- Incoming flow of passengers;

\subsection{Key features emerging from the observation and quick wins achieved}

Some of the key features that resulted in quick wins, recommendations which could improve the situation based on the observation, and potential influencing factors that could form the basis for further studies are briefed below.

(1). Passengers were generally instructed by the guard when they reached near the conveyor to remove their over coat, belt and shoes etc. This was found to cause some delay. Some of these passengers seem to be unaware that they need to remove these items for scanning.

\section{Remedial actions for quick wins:}

The guards were instructed to inform the passengers on the entry point itself about the need to remove over coat etc. This helped the passengers to be ready when they came near the conveyor.

(2). Serviced customers affecting process flow and performance were revealed. On completing the checking process, customers were taking a while to collect their belongings from the conveyor belt. They were busy putting on their belts, jacket etc while standing near the output conveyor obstructing other passengers from collecting their belongings from the conveyor. This affected the process flow often. This finding may not be revealed by any method other than observation.

Remedial actions for quick wins:

Provided a common seating area away from all lanes where people on collecting their belongings can go and sit and put on their shoes etc. This additional facility improved the efficiency of the process. 
(3). Different queuing systems were found to be in use such as single queue with multiple servers, multiple queues etc. at various terminals.

Remedial actions for quick wins:

It was recommended to follow strictly 'single queue with multiple servers' as this is the most efficient of all the queuing systems.

(4). Observation revealed the current situation entirely different from the planned one. The project team was informed about the designed and documented process, subsequent discussions brought out another version and, finally, what emerged after the critical observation was totally new. This highlights the popular view that any process is generally of three types. Only observation can reveal the status quo of the process.

Notable finding was related to the rotation of the process people. While the process people were taking positions by rotation every 20 minutes, sometimes the entire team had to wait for a team member from far off lane to come and take the position. As no activities were happening during these period (though 1 to 2 minutes), the queue started building up. Further detailed study was recommended (to carry out during the Measure phase) on team roaster and allocation of people.

(5). Travellers from other side of the globe (transit passengers), not knowing the current security requirement, usually carried two hand bags, and in some cases with soft drinks, water bottles, and liquid cosmetics in their hand bags. Many a time it led to arguments with the security personnel. Further, the passengers were asked to stuff the smaller bag into the bigger one. When this happened, more often than not, the screening machine camera rejected it. The 
full inspection was, hence, required to be carried out and that was invariably taking a longer time resulting in queue building up.

\section{Remedial actions:}

It was recommended to stop the practice of forcing two bags in one bag as this could be done after the screening. Information about the new security requirement to the other airlines and in turn to other countries was recommended.

(6). Observation helped to frame some hypotheses on the causes of variations. Guard skills vary. Sometimes the guard needed to call for another opinion or just took longer. Some items were more difficult to inspect, e.g. a bag in a bag to meet the requirement of 1 piece of hand luggage. The supervisor, for example, sometimes interrupted the screen guard to discuss the roaster. Level of skills at the 'screening check' also affected the queue, as the novice took generally longer time or disturb the other experienced person for his opinion to judge some doubtful cases. Hence the skills level and the number of skilled people in a lane were found to be influencing factors which needed to be statistically established.

Gender of the passengers and the number of children in the family were other potential factors to be studied. The items in the hand held bags will be different for female and female with children (compared to that of the male). Hence the proportion of different genders also could be a potential factor to be studied.

In relation to the point no.5 above, transit versus direct passengers was recommended as another potential factor for further studies in phase two (not covered in this case study).

\section{Managerial implications}


Both the multiple observations (greater number of stratified sampling) and the simultaneous observation by more than one observer helped to improve the understanding of the entire process and make valid judgement on the clues. It was also found that these followed by question sessions has greatly improved in understanding of the as-is-process. Especially for or a process which is so complex, such as this one, involving a large number of process operators, multiple process sequences and high volume, the practitioners or the Lean Six Sigma project leaders need to employ these special types of observations followed by questions sessions in order to bring out the features of the process being observed.

Observation as a tool has a profound impact on the organization in general and the people in particular. Observation plays an interesting and central role in the acquisition of knowledge. Observation promotes organizational learning and facilitates both employee involvement and the culture of continuous improvement (Liker, 2004). Observation yields information that helps to solve the organizational problems and identify more opportunities and new projects. The observation will be more effective if people are trained in observation skills, and so organizations should engage their members in activities like observing, collecting, sorting, sketching and interviewing through structured training. Observation is a natural gift with which human beings are bestowed. Observation and reflection on that observation contributes to effective learning and offers experiential learning to observers (Slack and Rowley, 2001). Therefore, people need to view observation as a self-directed and unconscious pursuit instead of as a management-directed process.

Finally, tools and techniques cannot be used effectively without proper training. It is all the more critical on techniques such as observation, which not only depends on basic skills and knowledge of the observation process, but also the observer's interpersonal skills, and prior knowledge about the process under investigation which will affect the outcome of the observation. 
Tools and technique are only a means to solve the problem, and any one single tool most of the time, used in isolation, cannot help solve the problem in hand totally and effectively. Proper selection of tools and techniques and competency in their application will enhance the overall effectiveness of the problem-solving process.

\section{Future research agenda}

The proposed approach was applied and tested in a transactional Lean Six Sigma project. The approach helped to understand the process and indeed it helped to prepare a data collection plan to make objective decisions at the end. Though it is found to be robust, its applicability in a wider context needs to be established through more case studies in both manufacturing and transactional environments.

It is recommended that case studies involving both mechanical and manual operations, and human interactions where the process needs to be understood in its total perspective, be taken up jointly by researchers and practitioners. These case studies can add to the body of knowledge and enhance understanding of how the actions of multiple participants in a process are organized jointly and how they affect the overall process outcome.

Furthermore, research is needed to better explain how an observer's prior knowledge affects their observation and conclusions drawn. This will help to bring out a framework which can be used for structuring training for effective observation.

\section{Conclusion}

This paper explained the concept of observation as a tool, its strength and limitations, and how it can be used effectively in a Lean Six Sigma context drawing on experiences from social science research and Lean. Based on a real case study, the paper explored how observation 
contributes towards achieving the twin objectives of both improving process efficiency and reducing the process variability in a Lean Six Sigma context. Although observation as a tool has certain limitations, this case study has found that observation triggers the problem-solving by making the observer understand the status quo of the process, offering some quick wins along the process and facilitating the generation of a set of hypotheses on the causes of variations, thus enhancing the power of Lean Six Sigma.

\section{References}

Antony, J. and Banuelas, R. (2002), Critical success factors for the successful implementation of six-sigma projects in organizations, The TQM Magazine, Vol. 14 No.2, pp.92-99.

Bicheno, J. (1999), The New Lean Tool Box, Picsie, London.

Bryman. A. (2001), Social Research Methods, Oxford University Press. London.

Conan Doyle, A. (1891) A Scandal in Bohemia, The Strand Magazine.

George, M. (2002), Lean Six Sigma: Combining Six Sigma Quality with Lean Speed. McGrawHill, New York, NY.

Harry, M. and Schroeder, R. (2000), Six Sigma, The breakthrough Management Strategy Revolutionizing the World's Top Corporations, Currency, New York.

Kumar, M., Antony, J., Madu, C.N., Montgomery, D.C., Park, S,H. (2008), Common myths of Six Sigma demystified, International Journal of Quality and reliability Management, Vol.25No.8, pp.878-895.

Liker, J.K. (2004), The Toyota Way-14 Management Principles from the World's Greatest Manufacturer, McGraw-Hill, New York, NY.

Machamer, P.K. (1970), Observation, Proceeding of the Biennial Meeting of the Philosophy of Science Association, Vol.1970.pp.187-201.

Malhotra, N. (1999), Marketing Research: An Applied Orientation, Prentice-Hall, London.

Martinko.M.J. and Gardner.W.L. (1985), Beyond Structured Observation: Methodological Issues and New Directions, The Academy of Management Review, Vol. 10, No. 4 (Oct., 1985), pp. 676-695

McCall, G.J.(1984), Systematic Field Observation, Annual Review of Sociology, Vol.10. pp. 263-282.

Mintzberg, H., (1973), The nature of Managerial Work, Harper and Row, New York.

Mintzberg, H. (1979), An emerging Strategy of "Direct" Research, Administrative Science Quarterly, Vol.24. No.4. pp. 582-589. 
Montgomery, D.C. and Woodhall, W.H,(2008), An Overview of Six Sigma, International Statistical Review, 76, 3, 329-346.

Pande, P.S., Neuman, R.P., Cavanaugh, R.R. (2000), The Six Sigma Way, How GE, Motorola, and other Top Companies Are Honing Their Performance, McGraw Hill, New York.

Rowley, J.(2004), Researching people and organizations, Library Management, Vol.15, No.4/5, pp.208-214.

Saunders.M., Lewis,P., Thornhill. A. (2000), Research Methods for Business Students, Prentice Hall, Harlow, England.

Slack, F. and Rowley, J. (2001), Observation: Perspectives on Research Methodologies for Leisure Managers, Management Research News, Vol.24, No.1/2.pp35-42.

Standard, C. and Davis. D. (1999), Running Today's Factory: A Proven Strategy for Lean Manufacturing, Hanser Gardner Publications, Cincinnati, OH.

Torretti, R. (1986), Observation, The British Journal for the Philosophy of Science, Vol. 37, No. 1 (Mar., 1986), pp. 1-23.

Weick, K.E., (1968), Systematic Observational methods. In Handbook of Social Psychology, 2 nd ed. (Eds.): Lindsey, E. and Aronson, E. 2 : 357-451, Addison-Wesley, Reading, Masss.

Womack, J. P. and Jones, D. T. (2003), Lean Thinking, Simon \& Schuster, London.

Womack, J.P., Jones,D.T. and Ross, D. (1990), The Machine That Changed the World, Maxwell Macmillan International, Ney York, NY. 
Table 1. Strengths and Limitations of 'observation'

\section{Strengths}

1. During the observation, the observer does not disturb the process or the people that are part of the process.

2. Observation helps to identify the origin of the problem, its location and the people who are responsible for the problem.

3. It helps to clarify and understand the problem in the first instance and helps even to define the problem accurately in some cases. A general saying is that 'a problem well defined is a problem half solved'.

4. More reliable information of the events or the process are obtained through observation as it reveals what is actually happening as against what people say about, or expect of, the process or problems.

5. Observation provides greater precision on the various elements of the events, facilitates greater understanding of the problem in proper perspective, and helps the project team to focus on the problem effectively.

\section{Limitations}

1. Generally, the output will be qualitative in nature, as putting it in quantifiable terms for easy understanding might pose problems on the part of the observer, as the findings \& the knowledge gained are mostly tacit in nature.

2. On sensing the observation, the process people may change their behaviour (Hawthorne Effect). Hence identification of the exact nature of the problem will be difficult. Furthermore, the observer needs to have good interpersonal skills, especially if they need to get clarification on the observed actions of some process members.

3. The observer needs to have good memory skills and observation power, as they need to observe and at the same time to record either in their memory or by noting down the details of observation.

4. Generally, the cognitive information, such as attitude, beliefs and inner feelings of the process members cannot be observed, especially in transactional settings. Such information is required in order to take suitable actions for improvement on the human side of the problem.

5. The outcome or the learning and findings from observation, can be affected greatly by what the observer chooses to observe, the framework which is pre-decided and the team as well as by the observer's knowledge, priorities or preconceptions, values etc. (Rowley, 2004). 